\title{
PLAN DEL CIERRE DE LA RELAVERA COMUNITARIA “EL TABLÓN”, PROVINCIA DEL ORO, ECUADOR.
}

\section{Closure plan for the community tailings dam "EI Tablón", EI Oro province, Ecuador.}

Núñez Romero Jorge Alberto* (iD), Burbano Morillo Danny Santiago iD, Jácome Calderón Juan Francisco iD.

Universidad Central del Ecuador, Facultad de Ingeniería en Geología, Minas, Petróleos y Ambiental, Quito, Ecuador.

*jorge_a_nunez_r@hotmail.com

$\mathrm{R}$ esumen

Se estableció un plan de cierre para la Relavera Comunitaria El Tablón (RCET), ubicada en la provincia de El Oro - Ecuador, afectada por problemas técnicos durante la operación en relación a; la metodología constructiva en lo que concierne a la depositación del relave conformando plataformas inestables que sobrepasan la altura del dique $( \pm 25 \mathrm{~m})$, además del daño del sistema integral del drenaje de fondo, el impacto visual y paisajístico. Se desarrollan dos aspectos: el primero es la elaboración de un modelo geológico - geotécnico de la relavera mediante información obtenida de: $2085 \mathrm{~m}$ de líneas de tomografía eléctrica, $1390 \mathrm{~m}$ de líneas de sísmica de refracción, $100 \mathrm{~m}$ de sondeos eléctricos verticales y $150 \mathrm{~m}$ de sondeos con recuperación de núcleos, aproximadamente $20 \mathrm{~m}$ de calicatas y estudios in situ. Segundo, se proponen obras que mitiguen los daños que produce el mal manejo de la relavera como: la estabilización de las plataformas con el relleno hasta una cota de cierre (696 m.s.n.m.); la implementación de técnicas de fitorremediación, reforestación y la construcción de canales de desvío. Finalmente, es importante insistir en el diseño y construcción de una planta de tratamiento de agua con lixiviado.

Palabras claves: Cierre de relavera, relave, fitorremediación, estabilidad, auscultación, compactación.

\section{A bstract}

A closure plan was established for the El Tablon Community Relavera (RCET), located in the province of El Oro - Ecuador, affected by technical problems during the operation in relation to; the constructive methodology regarding the deposition of the tailings forming unstable platforms that exceed the height of the dike $( \pm 25 \mathrm{~m})$, in addition to the damage to the integral system of the bottom drainage, the visual and landscape impact. Two fundamental aspects are developed; The first is the elaboration of a geological-geotechnical model of the tailings dam, through the information obtained from: 2,085 m of electrical tomography lines, 1,390 m of refraction seismic lines, $100 \mathrm{~m}$ of vertical electrical soundings and $150 \mathrm{~m}$ of drilling with core recovery, approximately $20 \mathrm{~m}$ of pits and insitu studies (geological mapping and geotechnical characterization). As a second aspect, works are proposed to mitigate the damages caused by the mismanagement of the tailings facility, such as; the stabilization of the platforms with the fill up to a closing level (696 m.a.s.l.) to ensure the stability of the dike and the good management of the runoff water. On the other hand, the implementation of phytoremediation techniques, reforestation and the construction of diversion channels that are part of the design of a park with recreational areas and an auscultation system that guarantees the stability of the tailings dam in the long term. Finally, it is important to insist on the need for the design and construction of a water treatment plant with leachate.

Keywords: Tailings closure, tailings, phytoremediation, stability, auscultation, compaction. 


\section{INTRODUCCIÓN}

Según datos calculados hasta el año 2002, en el mundo existen alrededor de 3500 presas de relaves, de las cuales entre 1915 y 2010 se contabilizan hasta 251 accidentes donde 221 fueron publicados en los Boletines del Comité Internacional de Grandes Presas (ICOLD), es decir que han representado una relevancia importante; por el impacto ambiental o económico ocasionado en el lugar de operación (1). Proyecciones realizadas por expertos del Centro para la Ciencia en la Participación del Público de Montana y gestores del medio ambiente en Maine - EEUU, indican que las roturas de relaves "muy serias" se registrarían a partir de 2011 una por año, teniéndose registro de 5 desastres hasta 2016; las cuales representan el derramamiento de al menos 1 millón de metros cúbicos de residuos mineros (2).

Según portales de noticias como New York Times y Deutsche Welle, los accidentes como los ocurridos en el distrito de Minas Gerais en 2015 (Marianas) y 2019 (Brumadinho) en Brasil, se han catalogado como los desastres ambientales de mayor trascendencia en Latinoamérica en los últimos 10 años, ocasionando alrededor de 280 muertes, más de 100 kilómetros cuadrados de áreas contaminadas, además de 84.367 demandas y un monto superior a 700 millones en multas para las empresas mineras $(3,4)$.

Según, Oldecop (1) las causas más relevantes para el fallo de las presas de relaves, son: deslizamiento del talud, terremotos, desbordamiento, problemas de cimentación, sistema de drenaje, falla por problemas en las estructuras auxiliares, erosión del dique, subsidencias o colapso del terreno.

Kieran (2) destaca que la reducción de costos y el método de construcción es el factor determinante en casi todas las causas de inestabilidad de las relaveras, donde las empresas mineras buscan mantener ganancias en el mercado de los minerales reduciendo así el costo de monitoreo y control ambiental durante y post operaciones.

El Consejo Internacional de Minería y Metales, (5) indica que en cada región donde se construyen estas estructuras debe existir regulaciones y manuales que se apliquen a cabalidad en miras a impedir cualquier desastre ambiental y procurar la preservación del ecosistema. Manuales de manejo de relaves mineros aplicados en Perú y Chile, referentes mundiales en minería, promueven la importancia de aplicar prácticas responsables en todas las fases mineras mitigando la degradación ambiental que la actividad minera produce (6).

También es necesario tener en mente que, se ha mencionado que accidentes en relaveras como: Represa Bento Rodriges en Minas Gerais, Brasil o el ocurrido en Barranco Colorado, Zhumiral, Azuay-Ecuador han sido provocados por acción de "venganza humana" de personas que conocían de esas infraestructuras al detalle (4).

La construcción de la Relavera Comunitaria El Tablón (RCET) inicia en el 2013, en uno de los distritos mineros más antiguos del Ecuador (Piñas - Zaruma - Portovelo), donde operan alrededor de 85 plantas de procesamiento mineral para la obtención de oro. Por varios años las plantas de beneficio, a pesar de contar con permisos ambientales, descargaban material de relave con alto contenido de metales pesados al río Calera - Amarillo, siendo el afluente principal de la cuenca Puyango - Tumbes. Esto provocó una demanda internacional por parte de la República del Perú, al constatar contaminación de metales pesados en las aguas del río Tumbes, utilizada para el riego y uso doméstico de sus pobladores. (7)

A partir del 2012 el gobierno ecuatoriano se comprometió en dar una solución inmediata a la problemática detectada en el cantón Portovelo y plantea como acción emergente la construcción de la Relavera Comunitaria El Tablón para acoger un volumen aproximado de 5'565 $248 \mathrm{~m}^{3}$. Los estudios estuvieron a cargo del INIGEMM en el año 2012 y la construcción fue ejecutada entre enero de 2013 y marzo 2014 por el consorcio APR. En mayo de 2014 la relavera entro en operación con la siguiente infraestructura: dique de materiales sueltos compactado, drenes principales, laterales, piscina desarenadora, infraestructura de bombeo que permiten según el diseño, controlar el relave y sus lixiviados. (Figura 1) 


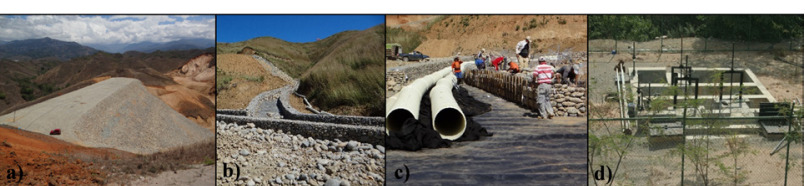

Figura 1. a) Vista panorámica de la presa (mayo 2014), b) Construcción del sub - dren principal y lateral, c) Estructura drenante para recoger agua con lixiviado. d) Caja hidráulica de distribución de agua con lixiviado y de escorrentía.

Las problemáticas en relación al diseño y operación son; incertidumbre en la construcción del dique, no cuenta con planos As - built, se desconoce el tratamiento de la cimentación del dique y la implementación de estructura drenante en el cuerpo del dique. Los estribos donde se asientan los diques, son de material deformable (saprolito), este problema geológico podría provocar que uno de los estribos falle o se deslice el cuerpo del dique, derivando en la descarga acelerada del relave hacia la Quebrada el Salado, río Amarillo y río Tumbes (Perú).

La depositación de los relaves es anti - técnica, se realiza vertidos desde el borde superior hacia el vaso; conformando 3 plataformas sin compactar donde la cota de las plataformas están sobre los $20 \mathrm{~m}$ de la cota de la cabecera del dique, los taludes falsos de las plataformas (volteo de material) presentan indicios de inestabilidad por la falta de compactación y erosión por escorrentía superficial, provocando además el daño de la estructura drenante principal y secundaria (rotura) con el ingreso de relave al sistema drenante, dificultando el paso del agua de escorrentía.

El diseño para manejar el agua con lixiviado y el agua freática no contemplo la construcción de una planta de tratamiento de agua de lixiviado y el monitoreo del agua freática que se descarga a la quebrada El Salado. El impacto visual y paisajístico que genera la cobertura de relave y la carencia de un proceso metodológico de construcción para el depósito técnico de las arenas de relave. (Figura. 2, 3, 4, 5)

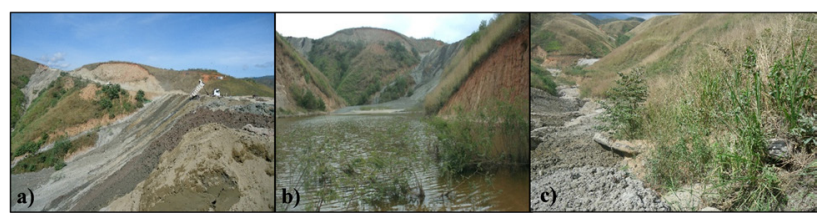

Figura 2. Año 2015, a) Vertido de relave desde la presa, b) Acumulación de agua dentro del vaso, evidenciando el mal funcionamiento de la estructura drenante, c) Terminal del tubo drenante sin conexión a caja hidráulica de recolección de agua de lixiviados. (8)

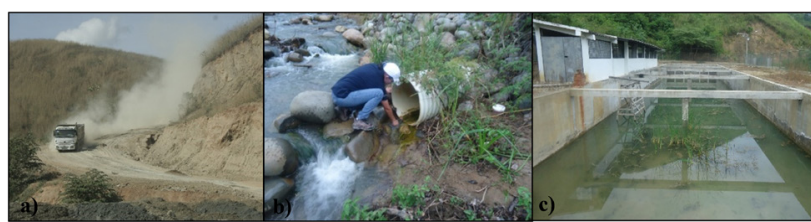

Figura 3. Año 2016, a) Nube de polvo de relave (polución), b) Termina del tubo donde se muestreo el agua que desemboca en la quebrada Salado, c) Piscina desarenadora con agua de lixiviado en donde no existe un tratamiento para mejorar la calidad química. (9)

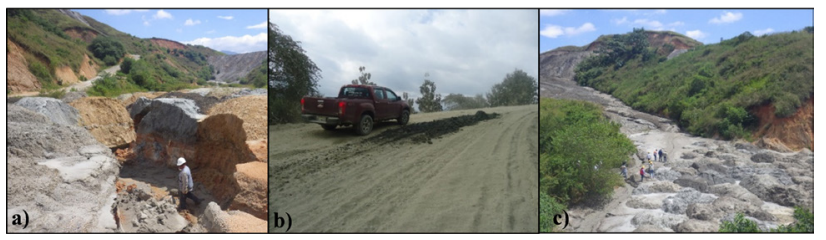

Figura 4. Año 2017, a) Erosión por agua de escorrentía sobre relaves dispuestos en la base sin compactación b) Derrame de relaves en la vía por inadecuado transporte, $\mathrm{c}$ ) Plataforma artificial $\mathrm{N}^{\circ} 3$ conformada por volteo de relave desde la vía perimetral hacia el vaso. Además, disposición de relaves sin compactación en la base.

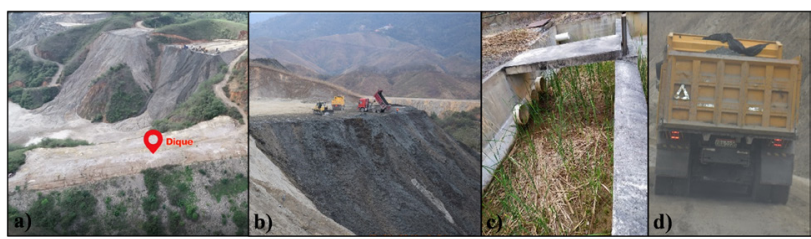

Figura 5. Año 2019, a) Vista panorámica del dique y 3 plataformas cuya cota superior supera $( \pm 25 \mathrm{~m})$ a la cota del dique. b) Trabajos de volteo de material conformando taludes susceptibles a movimientos en masa y erosión. c) Falta de mantenimiento de infraestructura drenante. d) La administración de la relavera no exige cubrir el balde de las volquetas con lona (derrame de relave en vías).

En consecuencia, esta investigación se destina al diseño de un plan de cierre para la RCET el cual minimice el foco de contaminación evidenciado en la quebrada El Salado a través de modelos geológicos - geotécnicos para la identificación de zonas inestables, modelos de depositación, planes de auscultación, aplicación de un método de fitorremediación, diseño de áreas recreativas y reforestación, que en conjunto permitan mitigar el impacto ambiental y crear una zona ecológicamente sustentable y turísticamente atractiva.

Para esto se cuenta con información bibliográfica en el ámbito geológico, geotécnico y operacional donde los modelos de estabilidad se fundamentan en; topografía escala 1:1000, $2085 \mathrm{~m}$ de líneas de tomografía eléctrica, 1390 m de líneas de sísmica de refracción, $150 \mathrm{~m}$ de sondeos de recuperación de núcleos, más de $100 \mathrm{~m}$ de sondeos eléctricos verticales (10), aproximadamente $20 \mathrm{~m}$ de calicatas (11). Por otra parte, levantamientos in - situ con la recolección de datos geotécnicos, estructurales usando equipos portables (martillo 
de Schmidt, penetrómetro y veleta de corte). La recolección de muestras de roca, suelo y relave permitió determinar en laboratorio sus parámetros índices, físico - mecánicos y químicos.

\section{MATERIALES Y MÉTODOS}

Para la ejecución de este proyecto se aplicó la siguiente metodología resumida en pasos:

1.- Recopilación bibliográfica de estudios ejecutados, se realiza un diagnóstico de documentos especializados con información de trabajos topográficos, geológicos, geotécnicos, hidrológicos, hidrogeológicos y ambientales sobre la relavera.

2.- Entrevista a testigos, se obtiene información a través de testimonios de técnicos y operadores de la RCET en relación a datos operativos y de relevancia técnica para la investigación.

3.- Interpretación de imágenes satelitales, se generan mapas temáticos que permitan visualizar los elementos constructivos de la RCET y la distribución espacial de zonas de depositación.

4.- Estudios geotécnicos in - situ en roca, suelo y relave, se levantaron estaciones geomecánicas y la resistencia de la roca mediante el uso del martillo de Schmidt. En suelo y relave se determinaron las propiedades resistentes mediante el uso de equipos portables (veleta de corte y penetrómetro).

5.- Muestreo de campo, se tomaron muestras selectivas de roca y relave para análisis de laboratorio. En roca se determinó la resistencia a la compresión simple de la matriz. En relave se ejecutaron ensayos de densidad, humedad, edométrico, corte directo y Proctor modificado. Además, se determinó el $\mathrm{PH}$ de muestras de agua de lixiviado en la planta desarenadora y en la quebrada El Salado.

6.- Modelo geológico - geotécnico, a partir de la información de estudios ejecutados y complementada con el trabajo de campo, se elaboran mapas y perfiles que detallan gráficamente las características geológico - geotécnicas de las diferentes litologías presentes en la zona de la RCET.

7.- Perfiles longitudinales y transversales para determinar la estabilidad de las plataformas de relave, con la referencia de los perfiles geológico - geotécnicos se incluyeron las plataformas de relave y se ejecuta una simulación para comprobar o descartar su estabilidad.

8.- Propuesta para el relleno hasta una cota de seguridad predeterminada, se diseñan modelos de depositación para el relave de la RCET, que garanticen la estabilidad del vaso y la seguridad del dique.

9.- Diseño del plan de cierre, se planifican obras para estabilizar física y químicamente al relave, mitigar su impacto visual, ambiental y la propuesta de uso turístico a la zona de la RCET.

\section{RESULTADOS}

Para el diseño del cierre técnico de la RCET, se desarrollaron varios estudios en relación al modelo geológico, la determinación de parámetros resistentes del macizo rocoso (roca fresca y roca meteorizada) y de los relaves. Además, se desarrolla un resumen de resultados en cuanto a estudios ejecutados para determinar la calidad química del agua.

\section{Modelo geológico - geotécnico}

La distribución espacial de la lito-estratigrafía se la interpreto mediante el modelamiento de 3 secciones geológico - geotécnicas (Figura 6), donde se incluyó investigaciones directas e indirectas como; $150 \mathrm{~m}$ de recuperación de testigos distribuidos en 6 sondeos, el contraste litológico diferenciado mediante $1390 \mathrm{~m}$ de sísmica de refracción, 2085 m de tomografía eléctrica (10) y geo - travesías donde se evidencio que la predominancia litológica es de un ortogneis de moderada a extremada meteorización (suelo residual), intruídos por diques pegmatíticos, dioríticos y andesíticos (12). (Tabla 1) 


\begin{tabular}{ccccccc}
\hline Unidad Geológica & Espesor $(\mathbf{m})$ & RQD $(\%)$ & Meteoriz. & RMR (Valorización) & Resist. Eléctrica $(\boldsymbol{\Omega}-\mathbf{m})$ & Conduct. Eléctrica $(\mathbf{m} / \mathbf{s})$ \\
\hline Saprolito & $15-25$ & $\begin{array}{c}\text { Regular } \\
(75-51)\end{array}$ & Alta & Mala $(40-21)$ & $300-700$ & $140-500$ \\
\hline $\begin{array}{c}\text { Macizo rocoso } \\
\text { (MRX MET.) }\end{array}$ & $>25$ & $\begin{array}{c}\text { Regular } \\
(75-51)\end{array}$ & Moderada & $\begin{array}{c}\text { Regular } \\
(60-41)\end{array}$ & $700-50000$ & $>2700$ \\
\hline
\end{tabular}

Tabla 1. Características geotécnicas y geofísicas de las unidades lito-estratigráficas de la RCET.

En relación a la geología estructural, la roca metamórfica presenta un rumbo preferencial $\mathrm{N} 60^{\circ} \mathrm{O}$ con buzamiento fuerte de $78^{\circ}$ hacia el SO (Ver Figura 6), el macizo presenta 3 familias de discontinuidades donde el levantamiento de 37 estaciones geomecánicas concluye que la calidad del macizo rocoso general, según la clasificación geomecánica de Bieniawski, 1985, se encuentra entre una roca clase III (Moderada) y roca IV (Mala) (13).

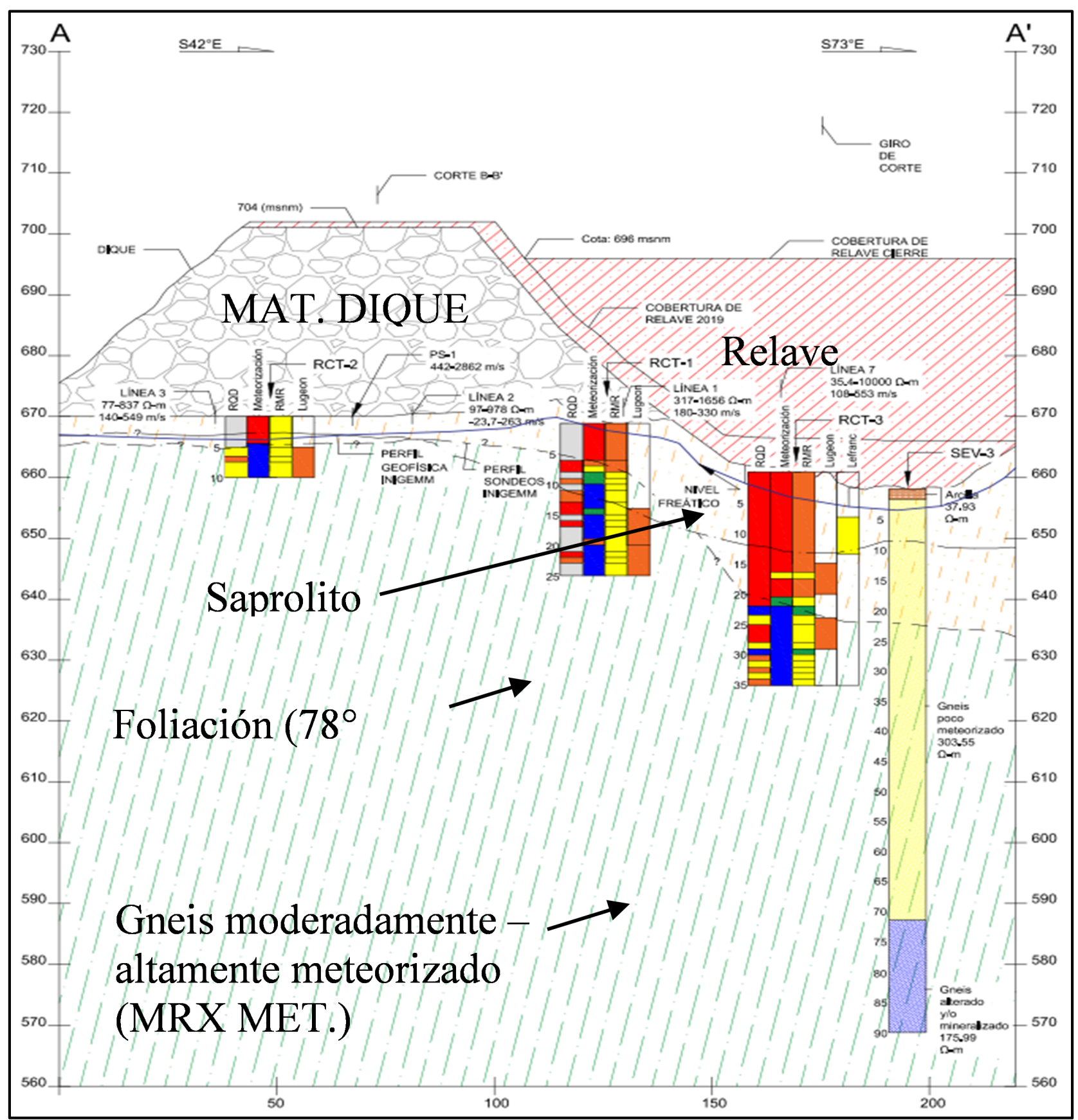

Figura 6. Sección geológico - geotécnica, donde se interpreta la calidad del macizo rocoso y niveles de meteorización en profundidad, con el uso de per foraciones y geofísica. Nota: Material de relave (MRV), material que conforma el dique (MAT. DIQUE), gneis moderadamente - altamente meteorizado (MRX MET.) 
Parámetros físico mecánicos del macizo rocoso, relave y materiales que conforman el dique. En la Tabla 2 se resume los resultados de ensayos geotécnicos realizados en material de relave (muestreados para las 3 plataformas; PT1, PT2
Y PT3) y macizo rocoso. Con asterisco $\left({ }^{*}\right)$ se identifica parámetros bibliográficos, con doble asterisco $\left.{ }^{* *}\right)$ se identifica parámetros resistentes y deformaciones calculados mediante el criterio empírico de Hoek - Brown (14).

\begin{tabular}{|c|c|c|c|c|c|c|}
\hline Muestra & Densidad $(\gamma) \mathbf{K N} / \mathbf{m}^{3}$ & Cohesión $(\mathbf{c}) \mathbf{K N} / \mathbf{m}^{2}$ & Ángulo de fricción $(\varphi)$ & Humedad $(\%)$ & SUCS & AASHTO \\
\hline Saprolito & $25^{*}$ & $156^{* *}$ & $35^{* *}$ & $10^{*}$ & $\mathrm{GW}^{*}$ & $\mathrm{~A}-1^{*}$ \\
\hline Roca MET. & $25^{*}$ & $240^{* *}$ & $44^{*}$ & $10^{*}$ & $\mathrm{GW}^{*}$ & $\mathrm{~A}-1^{*}$ \\
\hline Relave - PT1 & 20 & 40 & 54.16 & 11.4 & $\mathrm{SP}-\mathrm{SM}$ & $\mathrm{A}-4$ \\
\hline Relave - PT2 & 19.92 & 60 & 37.57 & 11.4 & $\mathrm{SP}$ & $\mathrm{A}-4$ \\
\hline Relave - PT3 & 20.04 & 50 & 49.09 & 12.1 & $\mathrm{SM}$ & $\mathrm{A}-4$ \\
\hline Mat. Dique & $25^{*}$ & $156^{*}$ & $35^{*}$ & - & - & - \\
\hline
\end{tabular}

Tabla 2. Propiedades físico mecánicas de saprolito, macizo rocoso (MRX), relave (MRV) y materiales del dique.

Nota: Con el símbolo $\left(^{*}\right)$ se indica valores bibliográficos y con el $\left(^{* *}\right)$ se indica valores obtenidos mediante el cálculo de criterio de rotura de Hoek \& Brown del software RocData. PT\# (Plataforma).

Análisis de calidad química del agua de lixiviado.

La Figura 7 se relaciona; el promedio de 18 metales analizados en 22 muestras de agua de; quebradas, piscina desarenadora del Tablón (recolección entre el 2015 hasta el 2019) con los límites máximos permisibles de la Normativa TULSMA Tabla 3 Anexo 1, Acuerdo Ministerial 097- A (15), donde 13 metales incumplen las concentraciones establecidas, a excepción de metales como la plata, arsénico, bario, berilo, cobalto y vanadio.

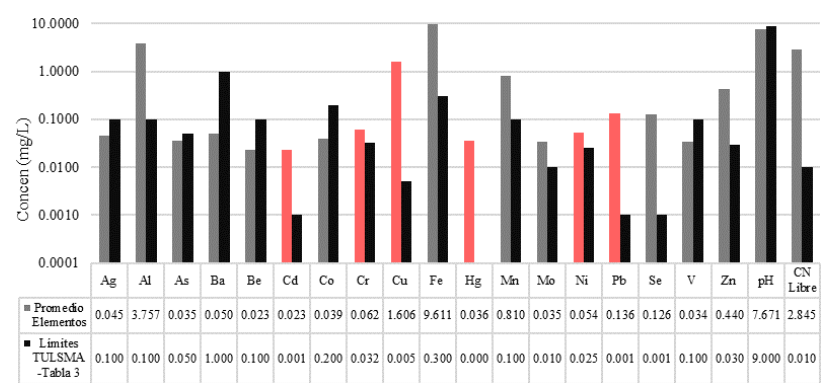

Figura 7. Comparación de concentraciones de elementos presentes en agua de lixiviado con los límites permisibles de la Normativa Ambiental TULSMA (Tabla 3). El resultado de cada elemento es el promedio del análisis de 20 muestras de agua tomadas en la Relavera el Tablón. (INIGEMM, 2015; IIGE, 2019).

Con rojo (Figura 7) se resalta algunos metales pesados que provocan efectos adversos en la salud humana, al sobrepasar el umbral de toxicidad. Por ejemplo; cadmio causa efecos carcinógenos; el cromo destruye las células del organismo derivando en cáncer; el cobre causa lesión renal, asma pulmonar; el mercurio produce parálisis, deformidad y enfermedades neuronales; el níquel origina cáncer pulmonar; el plomo provoca daño al sistema nervioso y enfermedades renales vasculares. $(17-21)$

\section{DISCUSIÓN}

\section{Análisis de Estabilidad}

El modelo geológico - geotécnico y los resultados de laboratorio permitieron modelar perfiles de estabilidad (equilibrio límite) pseudo - estáticos a través de las tres plataformas de relave concluyendo que la inestabilidad de los taludes artificiales presenta una rotura circular con un factor de seguridad promedio de 0.58 . (Figura 8 )

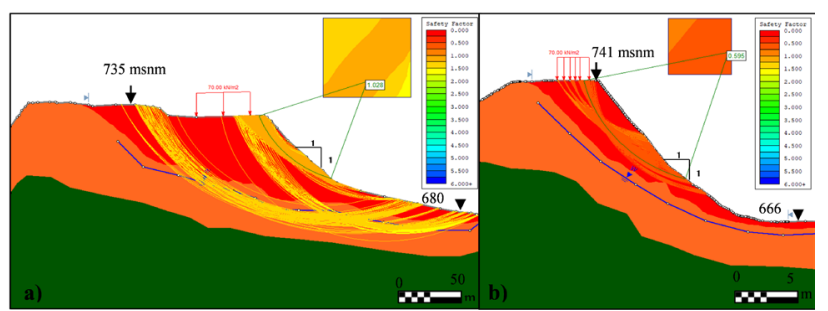

Figura 8. a) y b) Perfiles de estabilidad pseudo - estáticos en las plataformas 1 (FS: 0.595) y 2 (FS: 1.028). En verde se delimita el gneis moderada a altamente meteorizado, en naranja el saprolito y en rojo se muestra la conformación de las plataformas de relave. En azul se esquematiza el nivel freático.

Para ofrecer mayor estabilidad al vaso se plantearon dos alternativas, considerando que hasta el 2019 en la relavera se han depositado 2'044.798,00 $\mathrm{m} 3$, es decir; el 37\% de llenado, proyectando un tiempo de vida útil de 10 años (2029).

La primera alternativa considera el retiro de las tres plataformas y realizar el vertido de material desde cotas inferiores hasta cotas superiores (cota de cierre: 696 m s.n.m., Fig. 9) en fases ascendentes iniciando desde la cola de la relavera hacia el 
dique, donde la disposición de relave se debería configurar formando tongadas ( $5 \mathrm{~m} \times 4 \mathrm{~m} \times 0.5 \mathrm{~m}$ ) de material con una humedad que favorezca su máxima compactación.

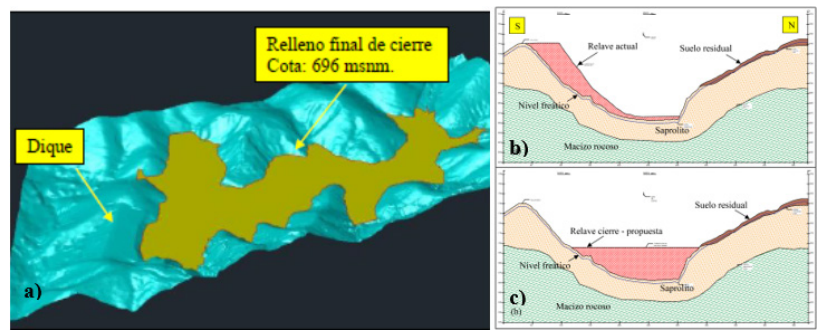

Figura 9. a) Vista isométrica SO de la RCET con el relleno de relave propuesto para el cierre (cota: 696 m.s.n.m.) b) Perfil trasversal (N-S) donde se evidencia la morfología del relleno de relave actual. c) Perfil trasversal $(\mathrm{N}-\mathrm{S})$ donde se evidencia la propuesta del relleno de relave hasta la cota 696 m.s.n.m.)

La segunda alternativa plantea como alternativa el construir 2 diques secundarios transversales al eje de la relavera conformados por relave y cemento, permitiendo controlar asentamientos diferenciales y el desplazamiento de los materiales hacia aguas abajo con el fin de no comprometer la estabilidad del dique principal. Para el cierre de la relavera (alternativas 1 y 2 ) se propone mantener una cota de relleno máxima en la 696 m.s.n.m. (Figura 10)

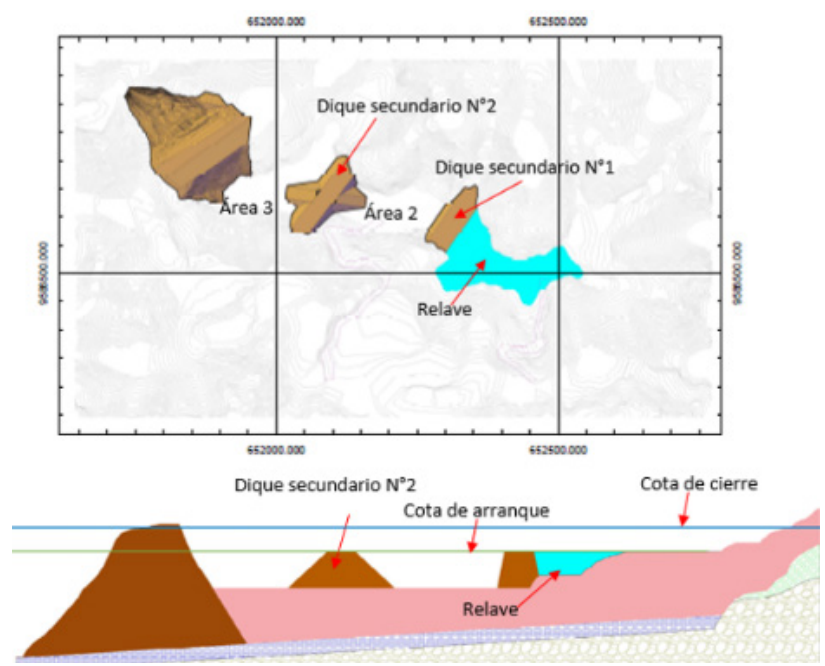

Figura 10. Vista en planta y perfil de la RCET, donde se ubican 2 diques secundarios. Fuente: Cobos, (22)

\section{Obras de Cierre}

Para disminuir el impacto ambiental y visual generado por el relave en la zona de la RCET se proponen varias obras, entre las cuales se tiene; el recubrimiento del vaso con $20 \mathrm{~cm}$ de arcilla para tapar al relave y sembrar especies fitorremediadoras. La fitorremediación consiste en la siembra de plantas con capacidades de bio - acumulación de metales pesados, se utilizarán especies como la sierrilla sensitiva (Mimosa púdica) y tabaquillo (Nicotiana glauca) $(23,24)$. Por otro lado, se plantea la reforestación al contorno al vaso de la relavera con el fin de devolver a la zona sus rasgos paisajísticos (25).

Es imperante la construcción de un canal de desvío perimetral que ayudará a conducir el agua de escorrentía del vaso, complementando las obras de estabilización de las plataformas de relave. El diseño de un parque en la parte central del vaso de la relavera que incluya elementos que generen un atractivo turístico para los pobladores de las comunidades aledañas. Finalmente, proponen medidas de auscultación con la instalación de una red de monitoreo topográfica, piezómetros Casagrande al pie del dique principal e inclinómetros en zonas susceptibles a movimientos en masa. (Figura 12).

Una de las obras más importantes es el diseño y construcción de una planta de tratamiento de agua de lixiviado conexa a la piscina desarenadora, que minimice el pasivo ambiental por la descarga de agua con elementos pesados (26).

Con el fin de minimizar el impacto ambiental, del agua de lixiviado producto de los residuos mineros, se plantea el diseño de una planta de tratamiento de aguas de lixiviado. En la figura 11 se observa, la ubicación espacial de la presa de materiales sueltos compactada, vaso de depositación de relave, estructura drenante (subdren principal y subdren secundario) y la ubicación donde se plantea desarrolla el proyecto de implementación de una planta de tratamiento de aguas de lixiviado.

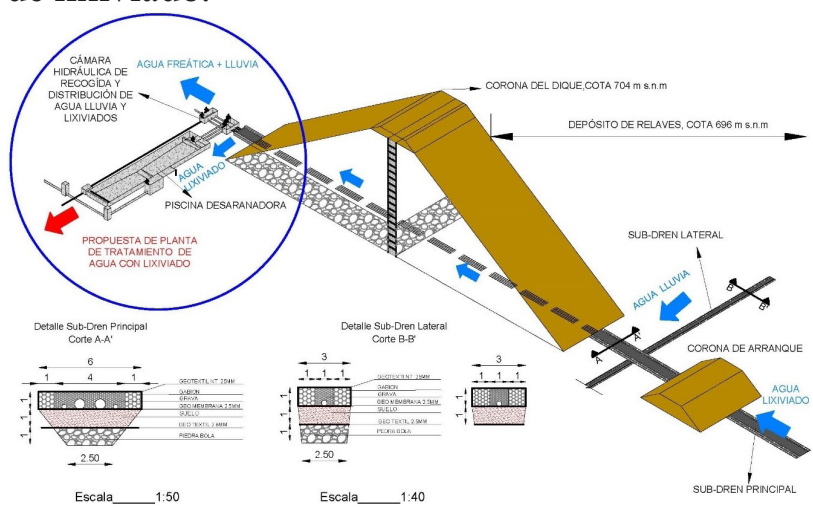

Figura 11. Vista Isométrica, donde se ubica la zona para implementar la planta de tratamiento de aguas de lixiviado. 


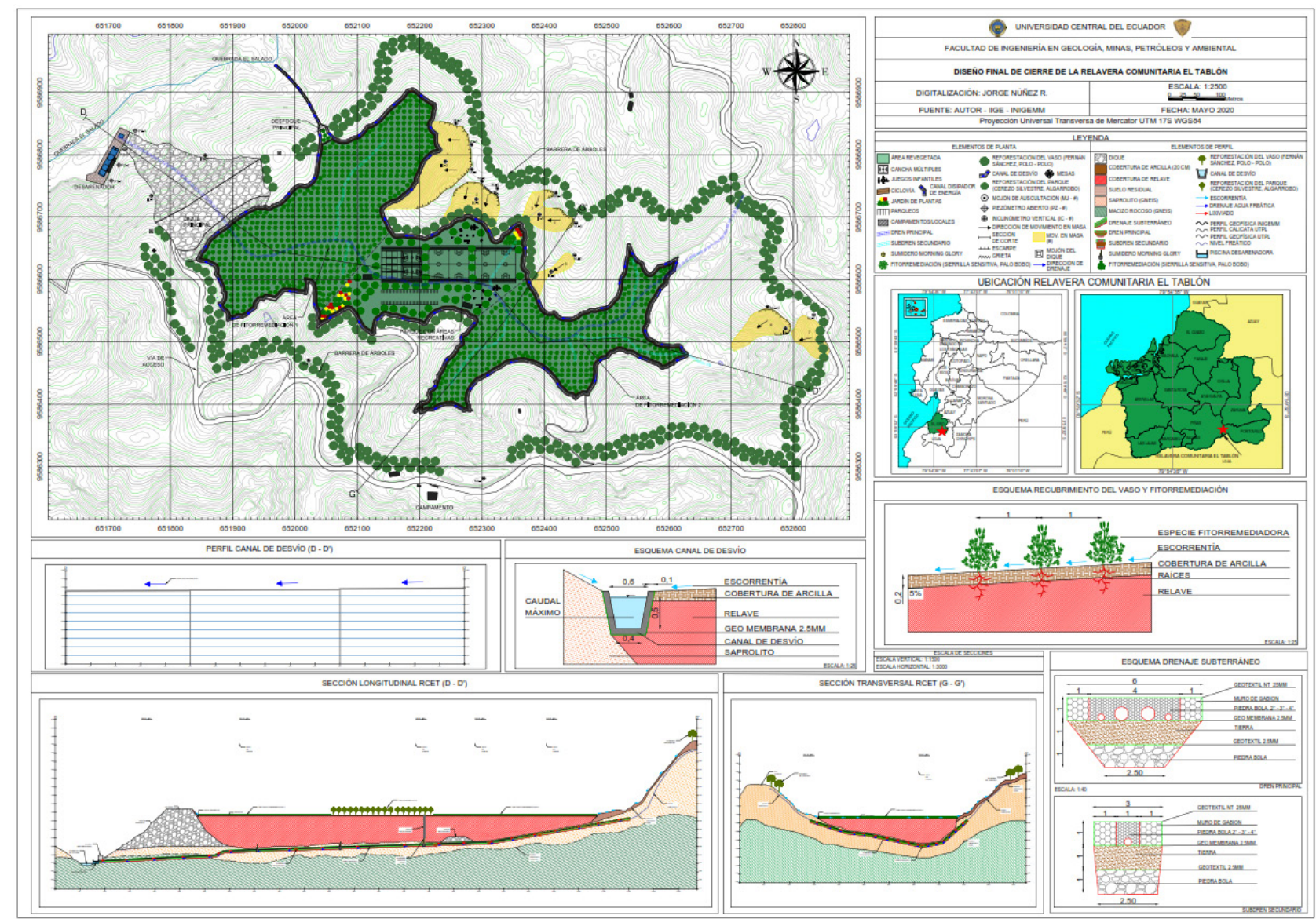

Figura 11. Diseño de cierre de la RCET

\section{CONCLUSIONES}

La RCET, desde su operación (mayo 2014) hasta octubre del 2019, no cuenta con una planificación de depositación técnicamente establecida, evidenciando las siguientes problemáticas:

- La RCET no cuenta con normativas internas de operación en relación al carguío, transporte y depositación del relave.

- La polución y la alteración paisajística es uno de los problemas más evidentes en la relavera, los cuales son divisados desde el poblado de Zaruma.

- Mal funcionamiento del sistema de drenaje principal y lateral.

- Contaminación por agua con lixiviado en la quebrada El Salado, donde existe una elevación abrupta de concentración en metales pesados como Al, Ba, Cd, Cr, Fe, Hg, Mn, Mo, Ni, Pb, Se, $\mathrm{Zn}$, que evidencian la falta de una planta de tratamiento de agua de lixiviado.
- No se respetó la cota de diseño de relleno (706 m.s.n.m.) donde las plataformas 1, 2 y 3 alcanzan alturas superiores manteniendo una diferencia aproximada de $25 \mathrm{~m}$.

- Se observó inestabilidad en los taludes falsos de las plataformas 1,2 y 3 , por no contar con una compactación adecuada, donde el vertido de las arenas se las realiza por volteo hacia el vaso de la relavera.

- Los problemas de inestabilidad son evidentes en el vaso de la relavera con la formación de múltiples movimientos en masa del tipo rotacional.

- Falta de auscultación geotécnica en la presa (cuerpo y estribos) y en las laderas que presentan inestabilidad.

- Falta de monitoreo ambiental en lo que concierne al control de parámetros establecidos en la norma TULSMA de calidad de agua y sólidos.

El levantamiento geológico de detalle, estudios directos e indirectos, permitieron la configura- 
ción del modelo geológico - geotécnico, identificando la distribución espacial de dos unidades lito - estratigráficas donde el gneis moderadamente meteorizado se ubica como basamento y suprayacendo a este, en forma discontinua, se desarrolla material saprolítico (suelo residual) con una potencia variable entre $15-25 \mathrm{~m}$.

El diseño de cierre se realizó en miras a mitigar y mejorar las condiciones actuales en las que se encuentra la RCET (2019), para lo cual: se plantea un modelo de cierre técnico de la relavera que incluye:

- Es imperante el diseño y construcción de una planta de tratamiento de agua con lixiviado.

- Fitorremediación para mitigar la contaminación producida por el relave, con el uso de plantas endémicas bioacumuladoras (Mimosa púdica y Nicotiana glauca).

- El relleno técnico hasta la cota de cierre 696 m.s.n.m. a través del peinado de las plataformas de relave (F.S.: 0.58) colocando el material a un mismo nivel con el objeto de proporcionar estabilidad a la presa de relaves.

- Se diseñó un canal de desvío de aguas pluviales para minimizar la acumulación de agua dentro de la relavera

- Generar una barrera perimétrica con reforestación para mitigar el impacto visual y paisajístico.

- El diseño de un parque con áreas recreativas para darle un uso turístico a la zona de la relavera y que constituya un beneficio para la comunidad del sector El Tablón.

- Implantar un sistema de monitoreo geotécnico para controlar las deformaciones en la presa, laderas y taludes de accesos viales.

- Ubicar perforaciones al pie de la presa con la instalación de piezómetros Casagrande con el fin de realizar un monitoreo periódico de la calidad del agua freática.

$\mathrm{R}$ eferencias

1. Oldecop L, Linares R. Los grandes desastres medioambientales producidos por la actividad minero-metalúrgica a nivel mundial : causas y consecuencias ecológicas y sociales. Rev del Inst Investig la Fac Ing Geológica, Minera, Met y Geográfica [Internet]. 2009;12:7-25. Available from: https://revistasinvestigacion.unmsm.edu.pe/index.php/iigeo/article/view/351

2. Kieran P. Las presas de desechos de las mineras crecen en tamaño y en riesgos. Wall Str J [Internet]. 2016;10:5. Available from: https://www.wsj.com/articles/las-represas-de-las-grandes-mineras-crecen-en-tamano-y-en-riesgos-1459790091

3. de Carvalho DW. The brumadinho dam rupture disaster, Brazil 2019: Analysis of the narratives about a disaster from the perspective of disaster law. Rev Estud Const Hermeneut e Teor do Direito [Internet]. 2020;12(2):227-38. Available from: https://papers.ssrn.com/sol3/papers.cfm?abstract_id=3659904

4. Costa BS. Acceso a la información digital en brasil en casos de accidentes: el ejemplo de la tragedia de Mariana. Veredas do Direito, Belo Horiz [Internet]. 2017;14:77-98. Available from: https://doi. org/10.18623/rvd.v14i30.1126

5. ICMM. Estándar Global de Gestión de Relaves para la Industria Minera. Glob Trailing [Internet]. 2020;42. Available from: https:/globaltailingsreview.org/wp-content/uploads/2020/08/global-industry-standard_ES.pdf

6. MINMINAS. Guía Ambiental Para el Manejo de Relaves Mineros. Ministerio de Minas y Energía. 2005;12:42. Available from: http://www.minem.gob.pe/minem/archivos/file/DGAAM/guias/relaveminero.pdf

7. Asanza AS. El Impacto de la Minería en el Distrito Minero Zaruma - Portovelo, y el Manejo de los Relaves Producidos en las Plantas de Beneficio, Ubicadas a lo Largo de los Ríos Calera y Amarillo de la Cuenca Binacional Puyango - Tumbes [Internet]. Universidad de Guayaquil; 2015. Available from: https://www.lareferencia.info/vufind/Record/EC_9147f2ee97d90bafd372d404553dcd13

8. INIGEMM. Inspección Diagnóstica de la Relavera Comunitaria “El Tablón” Portovelo, Provincia de El Oro. Quito-Ecuador; 2015.

9. INIGEMM. Inspección Geotécnica en la Operación de la Relavera Comunitaria "El Tablón” 
Portovelo, Provincia de El Oro. Quito-Ecuador; 2016.

10. INIGEMM. Estudios Complementarios para el Diseño de la Presa “El Tablón”, en el Distrito Minero Zaruma-Portovelo. Quito-Ecuador; 2013.

11. Guamán J. Estudio y Diseño de un Depósito de Relaves para el Almacenamiento de Relaves del Plan de Manejo de las Plantas de Beneficio en el Sector Minero Portovelo [Internet]. UTPL; 2009. Available from: https://1library.co/document/7qvk1rz5-estudio-diseno-deposito-relaves-almacenamiento-relaves-beneficio-portovelo.html

12. Núñez J. Plan del cierre de relavera comunitaria "El Tablón”, ubicada en el sector El Tablón, cantón Portovelo, provincia del Oro [Internet]. Universidad Central del Ecuador; 2020. Available from: http://www.dspace.uce.edu.ec/handle/25000/22292

13. Carrillo M, Linkimer L, Rodriguez Á, Zúñiga H. Clasificación geomecánica y análisis estabilidad de taludes del macizo rocoso coris, Cartago, Costa rica. Rev Geológica América Cent. 2002;26:91-6. 14. Hoek E, Carranza-torres C. El criterio de rotura de Hoek-Brown - Edición 2002 Hoek-Brown failure criterion - 2002 Edition. RocScience Inc [Internet]. 2002;(March 2016):1-8. Available from: nhttps://www.researchgate.net/publication/255644086

15. MAE. Norma de la Calidad Ambiental del Recurso Suelo y Criterios de Remediación para suelos contaminados. Minist del Ambient del Ecuador Recur Suelo, Libr VI Anexo 2 [Internet]. 2020;341-70. Available from: https://maeorellana.files.wordpress.com/2015/11/anexo-2-suelo.pdf

16. IIGE. Diagnóstico del Estado Actual de la Estabilidad y Operación de la Relavera Comunitaria El Tablón (RCET), Portovelo; Provincia de El Oro. Quito-Ecuador; 2019.

17. Argudín MA, Hoefer A, Butaye P. Heavy metal resistance in bacteria from animals. Res Vet Sci [Internet]. 2019;122:1-57. Available from: https://doi.org/10.1016/j.rvsc.2018.11.007

18. Morais Vasconcelos P, Branco R, Romeu F. Chromium resistance strategies and toxicity: what makes Ochrobactrum tritici 5bvl1 a strain highly resistant. Biometals (2011) [Internet]. 2011;24:401-10. Available from: https://link.springer.com/article/10.1007\%2Fs10534-011-9446-1

19. Li R, Wu H, Ding J, Li N, Fu W, Gan L, et al. Transgenic merA and merB expression reduces mercury contamination in vegetables and grains grown in mercury-contaminated soil. Plant Cell Rep. 2020;39(10):1369-80.

20. Maurya PK, Malik DS, Yadav KK, Kumar A, Kumar S, Kamyab H. Bioaccumulation and potential sources of heavy metal contamination in fish species in River Ganga basin: Possible human health risks evaluation. Toxicol Reports [Internet]. 2019;6(January):472-81. Available from: https://doi.org/10.1016/j.toxrep.2019.05.012

21. Nesler A, DalCorso G, Fasani E, Manara A, Di Sansebastiano G Pietro, Argese E, et al. Functional components of the bacterial CzcCBA efflux system reduce cadmium uptake and accumulation in transgenic tobacco plants. N Biotechnol [Internet]. 2017;35:54-61. Available from: http://dx.doi.org/10.1016/j.nbt.2016.11.006

22. Cobos I. Propuesta para la guía metodológica de operación, control y mantenimiento de la relavera comunitaria El Tablón, ubicada en el cantón Portovelo, Provincia de El Oro [Internet]. Universidad Central del Ecuador; 2021. Available from: http://www.dspace.uce.edu.ec/bitstream/25000/23464/1/ UCE-FIGEMPA-COBOS ISAAC.pdf

23. Delgadillo-lópez AE, González-ramírez CA. Fitorremediación: una alternativa para eliminar la contaminación. Trop Subtrop Agroecosystems [Internet]. 2011;14(1870-0462):597-612. Available from: http://www.scielo.org.mx/scielo.php?script=sci_arttext\&pid=S1870-04622011000200002

24. Falasca S, Ulberich A. La maleza Nicotiana glauca ( Graham ) como cultivo energético en sectores áridos y semiáridos de Argentina. Zo Áridas [Internet]. 1814;15(1):148-68. Available from: https:// ri.conicet.gov.ar/handle/11336/35364\#: :text=Está aclimatada a climas áridos,insecticidas y apto para biodiesel.

25. Molina Y. Reforestation as Environmental Strategy for the Conservation of rivers and streams. 2019;13:128-99. Available from: https://redib.org/Record/oai_articulo2507701-reforestation-environmental-strategy-conservation-rivers-streams

26. Beltrán-rodríguez LN, Larrahondo JM, Cobos D. Emerging technologies for tailings disposal: opportunities for Colombian practice. Bol ciencias la Tierra [Internet]. 2018;44(1):5-20. Available from: http://www.scielo.org.co/scielo.php?script=sci_abstract\&pid=S0120-36302018000200005\&lng=en\&nr$\mathrm{m}=\mathrm{iso} \& \operatorname{tlng}=\mathrm{es}$ 